\section{Levamisole and $\mathrm{HB}_{\mathrm{S}} \mathrm{Ag}$ positive chronic persistent hepatitis}

\section{Sir,}

Chronic persistent hepatitis (CPH) is not a simple entity (Lancet, 1977) and sometimes it may show progression to chronic active hepatitis. In patients with type-B CPH, several authors have observed some depressed immunological functions, so that the hypothesis of an inadequate clearance of $\mathrm{HB}_{\mathrm{s}} \mathrm{Ag}$ by the immune system has been put forward for the persistence of antigenaemia and of liver damage (Eddleston and Williams, 1974).

Some authors have used levamisole (LMS) in the treatment of acute (Pár et al., 1977) and chronic persistent (De Crée et al., 1974; Verhaegen et al., 1977) $\mathrm{HB}_{\mathrm{s}} \mathrm{Ag}$ positive hepatitis because of its immunostimulant activity (Lancet, 1975), and report beneficial effects. Published data on this subject remain scanty and use of LMS in CPH must still be considered an open question.

We present some data on 5 children, aged 4-10 years, with $\mathrm{HB}_{\mathrm{s}} \mathrm{Ag}$-positive $\mathrm{CPH}$ having altered transaminase levels, histologically controlled, who were treated with LMS at a dose of $2 \mathrm{mg} / \mathrm{kg}$ per day for 3 consecutive days per week, for 4 weeks.

Immunological parameters were controlled before and 10 days after the end of the treatment (Table) and compared with normal values for our laboratory. Humoral parameters were controlled during treatment and for the next 5 months.

Table Mean $( \pm S E M)$ percentage of $T$ - and $B$-lymphocytes in the peripheral blood of 5 children with chronic persistent hepatitis before and after treatment with levamisole (LMS)

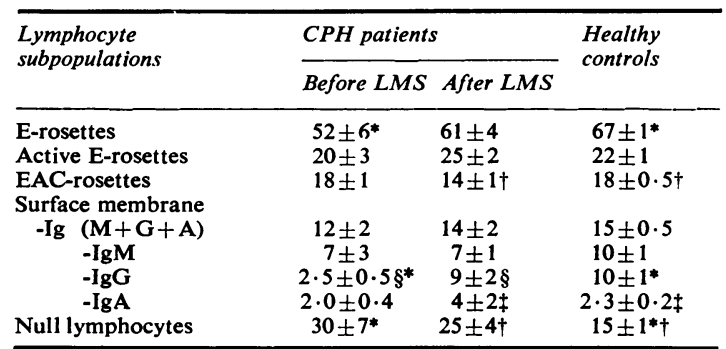

*P<0.001; †P<0.02; §P<0.01; $¥ \mathbf{P}<0.025$

Statistical evaluation for each immunological parameter has been performed with Student's $t$ test between values observed 'before LMS' and 'after LMS', 'before LMS' and 'healthy controls', and 'after LMS' and 'healthy controls', respectively. The reference marks indicate the groups compared and the respective significance.

In 4 patients we noted increased serum levels of transaminases (GPT and GOT) during LMS treatment, followed by a gradual fall. Serum IgM, IgG, and IgA increased in $4 / 5,3 / 5$, and $4 / 5$ patients respectively, although the difference before and after treatment was not statistically significant. Lymphocyte count was not significantly affected by the drug $\left(2.6 \pm 0.3 \times 10^{9} / 1\right.$; $2600 \pm 300 / \mathrm{mm}^{3}$ before and $2.0 \pm 0.3 \times 10^{9} / 1 ; 2000 \pm$ $300 / \mathrm{mm}^{3}$ after treatment).
As observed in other pathological conditions (Verhaegen et al., 1977) E-rosette-forming cells, which were significantly decreased before treatment, reached normal $\frac{\overline{0}}{9}$ values. Thymidine uptake after stimulation by 3 different $\overrightarrow{\vec{F}}$ concentrations of phytohaemagglutinin was significantly $\stackrel{\vec{F}}{+}$ higher than that found in normal controls before 0 treatment, and returned to normal after the course 흐 of LMS.

The percentage and the absolute number of EAC $\widetilde{\nabla}$ rosette-forming cells decreased significantly after LMS treatment as in previous observations (in vivo, Luzi et al., के 1977 ; in vitro, Wybran and Govaerts, 1977).

Null cells were increased in our patients and LMS treatment was followed by a decrease, but this was not significant.

Surface membrane-IgG bearing lymphocytes, at a very low level initially, increased to normal after treatment. ? This impressive increase in surface membrane-IgG- $\omega$ positive lymphocytes $\left(65 \pm 19 / \mathrm{mm}^{3}\right.$ before and $181 \pm 33 / 0$ $\mathrm{mm}^{3}$ after treatment) without change in the total number $/$ of B-lymphocytes (assessed by a polyvalent antiserum) $\perp$ may be a consequence of the known immunostimulatory 윽 effect of LMS on T-lymphocytes. The switch of antibody synthesis from IgM to IgG class induced by this drug $\infty$ (Renoux et al., 1976) may be analogous.

Despite the normalisation of numerous immunological parameters in our patients, which confirms the immunodulatory activity of LMS, the major humoral indices of the disease, antigenaemia and transaminase levels, were unaffected during 5 months' follow-up. This disappoine ing result could have been due to inadequate dose and/of duration of treatment but in view of the potentialle harmful effect of LMS-e.g. increased hepatocytolis during the treatment, even if transient, without disappearance of antigenaemia-our results have to be accepted as inconclusive. We think that the use of such a drug in this type of hepatitis still requires the most careful evaluation.

M. Masi, P. Paolucci, G. Timoncini, M. P. Fantini, G. LegGieri, F. Chiodo, and C. Franceschi Department of Pediatrics, Institute of Infectious Diseases, and Institute of General Pathology, University of Bologna, Via Massarenti m. 11, Bologna, Italy

\section{References}

De Crée, J., Verhaegen, H., De Cock, W., and Brugmans, J. (1974). The effect of levamisole on the immunologic response of HBAg-positive patients (abstract). Digestion, $10,306$.

Eddleston, A. L. W. F., and Williams, R. (1974). Inadequate antibody response to HBAg or suppressor T-cell defect in development of active chronic hepatitis. Lancet, 2. $1543-1545$.

Lancet (1975). Editorial: Levamisole. Lancet, 1, 151-152.

Lancet (1977). Acute and chronic hepatitis revisited. Review by an international group. Lancet, 2, 914-919.

Luzi, G., Franchi, F., and Aiuti, F. (1977). Un farmaco immunomodulatore: il levamisole. Folia allergologica et immunologica clinica, 24, 1-6. 
Pár, A., Barna, K., Hollos, I., Kovacs, M., Miszlai, Zs.. Patakfalvi, A., and Javor, T. (1977). Letter: Levamisole in viral hepatitis. Lancet, $1,702$.

Renoux, G., Renoux, M., Teller, M. N., McMahon, S., and Guillaumin, J. M. (1976). Potentiation of T-cell mediated immunity by levamisole. Clinical and Experimental Immunology, 25, 288-296.

Verhaegen, H., De Crée, J., De Cock, W., and Verbruggen, F. (1977). Restoration by levamisole of low E-rosette forming cells in patients suffering from various diseases. Clinical and Experimental Immunology, 27, 313-318.

Wybran, J., and Govaerts, A. (1977). Levamisole and human lymphocyte surface markers. Clinical and Experimental Immunology, 27, 319-321.

\section{Rifampicin therapy in shigellosis in infancy}

Sir,

The article under this title by Naveh et al. (Archives, 1977, 52, 960) deserves comment. It seems beyond doubt that the 11 children referred by the authors made up an exceptional group, both from the protracted course of the diarrhoea (1 to 4 months) and from the unexpected resistance in vitro to antimicrobial drugs. Diarrhoea due to shigella is usually a self-limited disease lasting a few days (Roy et al., 1975). As with other acute bacterial diarrhoeas, prolongation of its course is generally not due to the infection itself, but rather to sugar intolerance or to some form of the postgastroenteritis syndrome (Gribbin et al., 1976).

Failure to respond to furazolidone is not surprising; drugs not absorbable by the intestine can hardly affect the course of diarrhoea caused by invasive bacteria such as shigellae (Drachman, 1974). On the other hand, the reported failure to respond to treatment with chloranphenicol, ampicillin, or co-trimoxazole to which the shigella revealed in vitro sensitivity is astonishing and difficult to understand; such a situation has been only sporadically reported (Haltalin et al., 1972).

Commenting on the good results obtained with rifampicin, Naveh et al. state that it is 'a useful alternative preparation in drug-resistant shigella infection . . . a contention which they justify insufficiently.

The Archives has a world wide readership which includes many of the developing countries, and it is in these countries that shigellosis, tuberculosis, and other infectious diseases are prevalent. Rifampicin occupies an important place in the treatment of severe tuberculosis. A superficial reading of the article of Naveh et al. could lead to the more liberal use of rifampicin in disease other than tuberculosis, and this would be undesirable. For this reason, it seems that a more accurate and descriptive title such as 'Rifampicin therapy in protracted and resistant shigellosis in infancy' would have been preferable.

J. SAlazar de Sousa Department of Paediatrics, Hospital de Santa Maria, University of Lisbon, Lisbon, Portugal
References

Drachman, R. H. (1974). Acute infectious gastroenteritis. Pediatric Clinics of North America, 21, 711-737.

Gribbin, M., Walker-Smith, J. A., and Wood, C. B. S. (1976). Delayed recovery following acute gastroenteritis. Acta paediatrica Belgica, 29, 167-176.

Haltalin, K. C., Kusmiesz, H. T., Hinton, L. V., and Nelson, J. D. (1972). Treatment of acute diarrhea in outpatients. Double-blind study comparing ampicillin and placebo. American Journal of Diseases of Children, 124, 554-561.

Roy, C. C., Silverman, A., and Cozzetto, F. J. (1975). Pediatric Clinical Gastroenterology, second edition, p. 189. Mosby: St Louis.

Dr Naveh and co-workers comment:

We agree with Professor Salazar de Sousa that the group described in our paper was an exceptional one and this was the reason for using an unconventional antimicrobial agent. The assumption that protracted diarrhoea in our group might have been the result of sugar intolerance cannot be correct as in shigellosis the infection selectively affects the colon (Roy et al., 1975), which has nothing to do with the split and absorption of ingested sugars.

We did not suggest that rifampicin be used in a normal case of bacillary dysentery. We have used rifampicin in shigella septicaemia (Naveh and Friedman, 1973) and recently in a shigellosis situation where 11 infants had been crossinfected and we were urged to eradicate this infection from the nursery, and thus protect babies from being crossinfected. Furthermore, use of rifampicin in nontuberculous infections did not result in higher incidence of resistant strains of Mycobacterium tuberculosis in those countries where rifampicin was used in tuberculous and also nontuberculous infections (Acocella et al., 1977; Trallero et al., 1977).

Finally, we agree with Professor Salazar de Sousa that a more accurate and descriptive title for our paper might have been 'Rifampicin therapy in protracted and resistant shigellosis in infancy'.

\section{Y. Naveh, P. Strahovsky, and A. Friedman Department of Pediatrics $B$, Rambam Medical Centre, Haifa, Israel}

\section{References}

Acocella, G., Hamilton-Miller, J. M. T., and Brumfitt, W. (1977). Can rifampicin use be safely extended? Evidence for non-emergence of resistant strains of Mycobacterium tuberculosis. Lancet, 1, 740-742.

Naveh, Y., and Friedman, A. (1973). Rifampicin therapy in Gram-negative bacteraemia in infancy. Archives of Disease in Childhood, 48, 967-969.

Roy, C. C., Silverman, A., and Cozzetto, F. J. (1975). Pediatric Clinical Gastroenterology, second edition, p. 188. Mosby: St Louis.

Trallero, E. P., Casabona, N. M., Fuente, T. G., and Laguna, I. G. (1977). Letter: Rifampicin-for tuberculosis only? Lancet, 1, 956-957. 